\title{
From Eastern Europe
}

\author{
C P Bálint
}

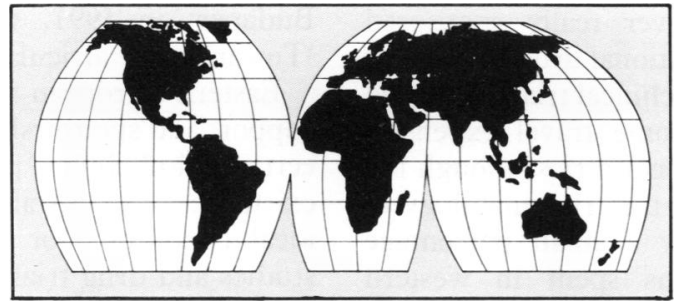

Eastern Europe was the site of fundamental revolutionary changes during 1989-90. As a result of 'glasnost' and 'perestroika' set in train by the Soviet Communist Party leader, Mikhail Gorbachev, the Potemkin walls of communism have fallen, the 'hard' and 'soft' dictatorships in the region have been overthrown by the people, partly in bloodless, partly in bloody revolutions. The road to democracy has been opened. East Germany has joined the Federal Republic and the ideals and practice of communism, even in the former 'Soviet Union', have been repudiated. It is understandable, therefore, that rheumatologists of this region-in addition to carrying out their everyday clinical and research workhave become interested and involved in these changes, sometimes to the extent of catalysing developments.

Exchange of political views as well as discussion of research issues became common at the many international rheumatology congresses and symposiums held in eastern Europe, and doubtless these exchanges contributed to the 'chain reaction' of revolution. It was, for example, of great importance that the Hungarian Association of Rheumatologists organised a quadrilateral symposium in Budapest in June 1989, at which delegates of the Federal and Democratic Republics of Germany first met officially together with the delegations of Austria and Hungary. The east German government strongly opposed this arrangement, but owing to the insistence of the Hungarian association, especially its president, Professor Béla Gömör, the east German officials accepted the meeting. The activity of Professor Gömör and the Hungarian association has been highly appreciated by the rheumatologists of unified Germany.

After these upheavals the eastern European countries now face a number of problems: difficulties with the economy, growing poverty, unemployment, chauvinism. The centralised, but poorly equipped, poorly financed, and even poorly organised health systems are unable to deliver sufficient health care. Previous resources are not now available and new resources have not yet taken their place. Growing inflation has had a drastic effect on eastern European countries and it is not yet known whether new resources will be available.

It is probably almost unbelievable for readers of the Annals to learn that the National Institute of Rheumatology and Physiotherapy (ORFI) in Budapest with its 1300 beds-including not only beds for rheumatology and rehabilitation, but also orthopaedic surgery, general surgery, ophthalmology, urology, etc, and with radiology facilities, laboratories, research departments, and outpatient clinics-has a budget of 550 million forints. This sum is equivalent to $£ 4230000$ and it includes salaries, research and education expenses, replacements, and investments. The amount of money available for each patient is 1070 forints $(£ 8 \cdot 20)$ a day. With prices nearing those in western Europe and an inflation rate of about $35 \%$, the absurdity of the situation is clear.

Medical research was never generously sponsored in communist countries; only the amount necessary to keep up appearances was spent. Only researchers and clinicians loyal to the regime were given resources and the results of research were never examined. In the so called 'soft' dictatorships (Yugoslavia, Hungary, Poland, and Czecho-Slovakia) even western grants were available for a restricted number of researchers aiming at developing ties between the divided parts of Europe. These grants enabled some researchers or centres not primarily supported by the communist governments to enter into first line rheumatology and immunology research. Owing to these ties, rheumatological study in the 'soft' dictatorships was better-though still not satisfying - than that in other communist countries.

In contrast, the relation between rheumatologists of different eastern European countries has been good. Interstate agreements led to study tours, visits, and exchange of researchers. Additionally, numerous joint research programmes were developed, though no outstanding results were achieved. The centralised health system in these countries would have provided good conditions for epidemiological studies and widescale clinical trials but, regrettably, in these countries treatment of rheumatology has been by physiotherapy and spa treatment and thus, unfortunately physiotherapy trials and research have not developed. Despite this the close collaboration of rheumatologists of eastern European countries has been fruitful.

The closest ties were developed among the rheumatologists of East Germany, CzechoSlovakia, Poland, and Hungary. After the fall of

\footnotetext{
XIIth European

Rheumatology,

Budapest 23, Pf 62 , H-1277, Hungary C P Bálint
} 
the communist regime the resources available for eastern European rheumatology have become uncertain. The centralised health system will, at least partly, be privatised as the post-communist governments are tending to cut down state support as much as they can.

In a situation fraught with economic difficulties it seems unlikely that treatment of rheumatology will receive priority. State support for research is declining rapidly and other systems of sponsorship have not yet been developed. The pharmaceutical industries of these countries have never really sponsored research. The big, international drug firms have certainly sponsored some clinical trials, financed a few grants, covered some travel expenses, even in eastern European countries, though the sum they spent in supporting rheumatology in these countries was only a small percentage compared with the sums spent in western European countries. Unfortunately, the fundamental changes in eastern Europe have not encouraged international pharmaceutical companies to invest more capital and provide more support for research in these countries.

The increasing costs of air fares and other forms of travel, the decreasing support of the state, the absence of earlier agreements allowing communication between clinicians and researchers of the previous communist countries have almost halted the movement of rheumatologists in eastern Europe, even within their own countries. Paradoxically enough, the fall of the wall, the removal of the iron curtain, the light of freedom do not support, but in contrast, hinder, free movement not because of bureaucratic regulations and red tape as previously but simply because of a lack of money. It would be ridiculous, if it were not so deeply regrettable, that only a few dozen rheumatologists from the eastern European countries were able to attend the XIIth EULAR congress, which was held in Budapest in 1991, the motto of which was 'Towards free articulation'.

Eastern European rheumatology badly needs support and sponsorship. Lack of resources will certainly kill clinical practice and research. The existence of a centralised system still provides ideal conditions for large scale epidemiology studies and drug trials, especially now that red tape and bureaucratic restrictions are no longer a hindrance. The brains in eastern Europe are no less bright and dedicated than in other parts of Europe, only cheaper. But we do need support from EULAR, ILAR, the drug industry, and the leagues of the more developed countries. We have strong arms to swim, as we have shown in the past, but we are tiring in the hopeless struggle against the waves.

'Save our souls' and minds! 